Case Report

\title{
A New Case of Prenatally Diagnosed Pentasomy X: Review of the Literature
}

\author{
Linda Maria Azzurra Pirollo, ${ }^{1}$ Leila Baghernajad Salehi, ${ }^{2}$ Simona Sarta, ${ }^{1}$ Marco Cassone, ${ }^{3}$ \\ Maria Vittoria Capogna, ${ }^{1}$ Emilio Piccione, ${ }^{1}$ Giuseppe Novelli, ${ }^{4}$ and Adalgisa Pietropolli ${ }^{1}$ \\ ${ }^{1}$ Section of Gynecology and Obstetrics, Academic Department of Biomedicine and Prevention and Clinical Department of Surgery, \\ Tor Vergata University Hospital, Viale Oxford 81, 00133 Rome, Italy \\ ${ }^{2}$ Laboratory of Medical Genetics, Polyclinic of Tor Vergata Foundation, Viale Oxford 81, 00133 Rome, Italy \\ ${ }^{3}$ Laboratory of Medical Genetics, University of Rome Tor Vergata, Via Montpellier 1, 00133 Rome, Italy \\ ${ }^{4}$ Genetics Section, Department of Biomedicine and Prevention, University of Rome Tor Vergata, Via Montpellier 1, 00133 Rome, Italy
}

Correspondence should be addressed to Linda Maria Azzurra Pirollo; lindapirollo@gmail.com

Received 2 December 2014; Revised 13 January 2015; Accepted 14 January 2015

Academic Editor: Olivier Picone

Copyright (C) 2015 Linda Maria Azzurra Pirollo et al. This is an open access article distributed under the Creative Commons Attribution License, which permits unrestricted use, distribution, and reproduction in any medium, provided the original work is properly cited.

Pentasomy $\mathrm{X}$ is a rare chromosomal abnormality probably due to a nondisjunction during the meiosis. Only four cases prenatally diagnosed were described until now. Our case is the fifth one prenatally diagnosed at 20 weeks of gestational age in a 39-yearsold woman. She underwent invasive prenatal diagnosis for her advanced maternal age without any other known risk factor. Amniocentesis performed at 17 weeks showed a female 49, XXXXX karyotype. The ultrasonographic examination revealed nonspecific signs of a mild early fetal growth retardation and no significant increased nuchal fold. The fetal autopsy and the Xray excluded major malformations. Prenatal diagnosis is often difficult due to the lack of indicative ultrasonographic findings and the rarity of described cases. The influence of the mother's age on the occurrence of penta-X syndrome has not been determined. Considering the lack of correlation between advanced maternal age and increased risk for pentasomy X, as well as the absence of typical echographic signs, evaluation of the inclusion of a noninvasive prenatal test (NIPT) that expands clinical coverage to include the $\mathrm{X}$ and $\mathrm{Y}$ chromosomes in routine prenatal diagnosis should be considered as well as three-dimensional ultrasound to detect any helpful indicative prognostic signs.

\section{Introduction}

Pentasomy X (49, XXXXX) is a very rare aneuploidy involving sex chromosome $\mathrm{X}$. It is characterized by a variable phenotype in females.

The described features in 49, XXXXX karyotype include severe mental retardation with delayed speech development, short stature, facial dysmorphisms, osseous and articular abnormalities, congenital heart defects, and skeletal and limb abnormalities [1]. The craniofacial anomalies may include microcephaly, micrognathia, plagiocephaly, hypertelorism, upslanting palpebral fissures, a flat nasal bridge, and ear malformations. The hands and feet are generally small and camptodactyly, clinodactyly, and radioulnar synostosis are common findings. Immunoglobulin anomalies and an increased susceptibility to infection have also been reported.

The incidence of pentasomy $\mathrm{X}$ is unknown because of rarity of this aneuploidy but some authors indicate about $1 / 85000$ comparing to $49, \mathrm{XXXXY}$ in males [2].

The pathogenesis of pentasomy $\mathrm{X}$ is not clear: this aneuploidy must arise as a result of a meiotic malfunction, either maternal or combined maternal and paternal in origin [3-5].

Only four pentasomy X cases were detected prenatally and the ultrasonographic findings are summarized in Table 1 [6-9]. 
TABLE 1: Review of the literature: cases prenatally diagnosed.

\begin{tabular}{|c|c|c|c|c|c|}
\hline $\begin{array}{l}\text { Case } \\
\text { report }\end{array}$ & $\begin{array}{l}\text { Maternal } \\
\text { age }\end{array}$ & Ultrasonographic findings & Invasive prenatal test & $\begin{array}{l}\text { Weeks of } \\
\text { pregnancy }\end{array}$ & $\begin{array}{l}\text { Autopsy report and fetal X-ray } \\
\text { scan }\end{array}$ \\
\hline $\begin{array}{l}\text { Martini } \\
\text { et al. } 1993 \\
{[6]}\end{array}$ & 39 years & $\begin{array}{l}\text { (1) Growth restriction } \\
\text { (2) Radioulnar synostosis }\end{array}$ & $\begin{array}{l}\text { Amniocentesis } \\
\text { performed after US scan }\end{array}$ & 18 weeks & $\begin{array}{l}\text { Hypertelorism, slight } \\
\text { mongoloid slant, radioulnar } \\
\text { synostosis, and hypoplastic } \\
\text { ovaries depleted of oocytes }\end{array}$ \\
\hline $\begin{array}{l}\text { Myles } \\
\text { et al. } 1995 \\
{[7]}\end{array}$ & 26 years & $\begin{array}{l}\text { (1) Dandy-Walker malformation } \\
\text { (2) Hydrocephaly } \\
\text { (3) Ventricular septal defect } \\
\text { (4) Hypertelorism } \\
\text { (5) Polyhydramnios } \\
\text { (6) Growth restriction }\end{array}$ & $\begin{array}{l}\text { Amniocentesis } \\
\text { performed after US scan }\end{array}$ & 33 weeks & $\begin{array}{l}\text { NO (born at } 39 \text { weeks with } \\
\text { caesarean section and died at } \\
134 \text { days of age) }\end{array}$ \\
\hline $\begin{array}{l}\text { Cheng } \\
\text { et al. } 2008 \\
{[8]} \\
\end{array}$ & 29 years & Increased nuchal translucency & $\begin{array}{l}\text { Chorionic villous } \\
\text { sampling before US scan }\end{array}$ & 11 weeks & No \\
\hline $\begin{array}{l}\text { Aytac et al. } \\
2012[9]\end{array}$ & 26 years & $\begin{array}{l}\text { (1) Increased nuchal fold } \\
\text { (2) Pleural effusion } \\
\text { (3) Subcutaneous edema } \\
\text { (4) Ascites } \\
\text { (5) Bilateral hand clinodactyly }\end{array}$ & $\begin{array}{l}\text { Amniocentesis } \\
\text { performed after US scan }\end{array}$ & 17 weeks & No \\
\hline
\end{tabular}

\section{Case Presentation}

A 39-year-old healthy woman referred to the Prenatal Diagnosis Centre of Tor Vergata University Hospital, Rome, to undergo genetic amniocentesis at 17 weeks of pregnancy. The main indication to the procedure was advanced maternal age. She had a noncontributive history (4G2P) with a previous spontaneous miscarriage at 10 weeks between the two pregnancies. She was smoker (8 cig./day) with a weight of $75 \mathrm{~kg}$ (BMI 29.3). Before the procedure, the patient was evaluated with some blood tests (blood group, indirect Coombs test, HbsAG, HCV, HIV, VDRL, and TPHA), ultrasound exam, and vaginal swabs in order to predict a possible ascendant infection. Antibiotic prophylaxis (Azithromycin (Zithromax)) was administered as specific dose together with vaginal progesterone for six days prior to the procedure. Written informed consent was obtained. Amniocentesis was performed and the amniotic fluid sample was referred to the medical genetics department. Chromosomal analysis was performed in long-term amniotic fluid cultures from three separate tissue culture flasks. GTG- and CBG-banded metaphases were analysed and the karyotype was reported as $49, \mathrm{XXXXX}$ (Figure 1). The family was concerned with the results and, during the counselling, they were offered an ultrasound scan before the mother's decision. At 20 weeks of gestational age the ultrasonographic examination ruled out major fetal malformation. As minor finding there was a mild nuchal fold increase and a fetal growth at lower values than would be standard for the gestational age (Figures 2 and 3). The woman decided to terminate the pregnancy: the fetal X-ray scan and autopsy excluded significant morphological alterations (Figure 4). No subcutaneous oedema was described in the autopsy report; this finding evaluated prenatally could be transient as it was previously hypothesized [9].

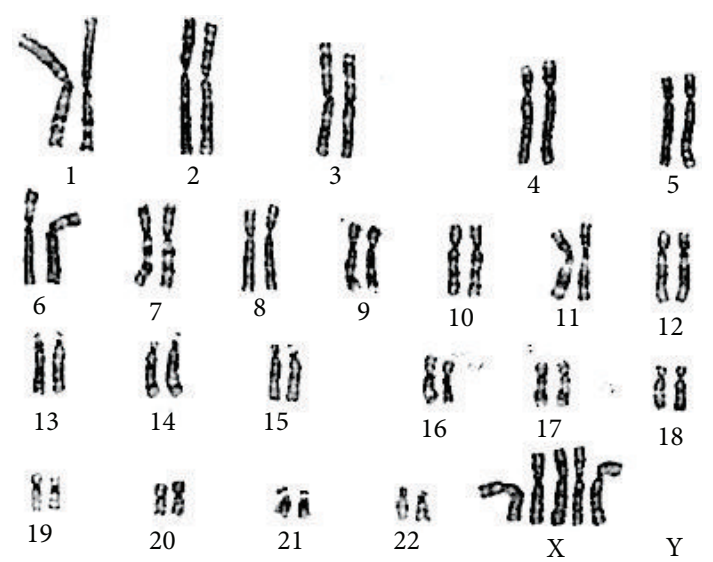

FIGURE 1: Fetal karyotype demonstrating pentasomy X.

\section{Discussion}

Pentasomy $\mathrm{X}$ is a rare aneuploidy with variable phenotype. A review of postnatal pentasomy $\mathrm{X}$ cases (26 cases) shows mental retardation and development retardation to be the only clinical aspects in common in all the cases reported in literature (Table 2, [10-32]).

It seems depending upon an $\mathrm{X}$ gene dosage defect due to an alteration of $\mathrm{X}$ inactivation mechanisms. It is also noteworthy that the female triple $\mathrm{X}$ shows normal phenotype.

The rarity of the condition and the few data available make genetic counselling complicated in order to give detailed clinical information to the patient about the disorder; so a multidisciplinary counselling is requested involving obstetrical-gynecological evaluation to identify echographic patterns. 


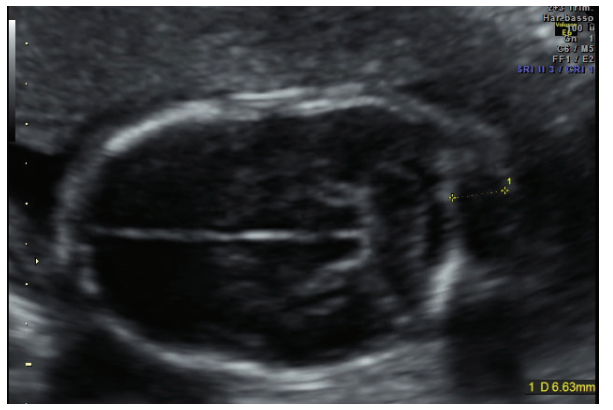

(a)

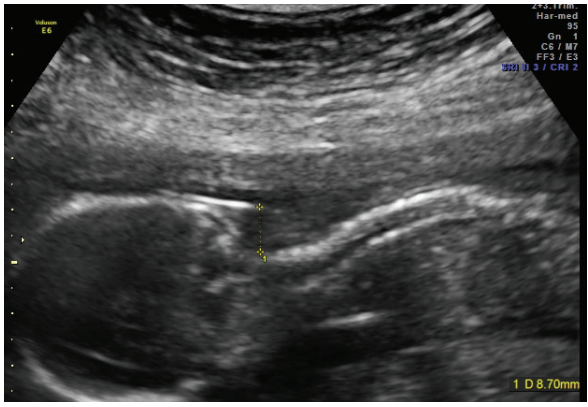

(b)

FIGURE 2: Increased nuchal fold in a transverse view (a) and in a longitudinal view (b) of the fetal head. The maximum value obtained was $8.7 \mathrm{~mm}$. Such subcutaneous oedema was not described in the autopsy report.

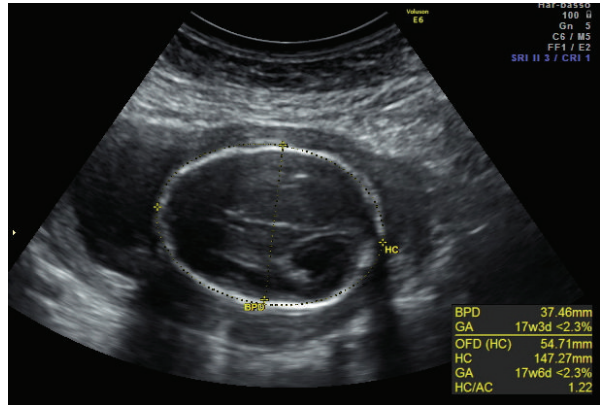

(a)

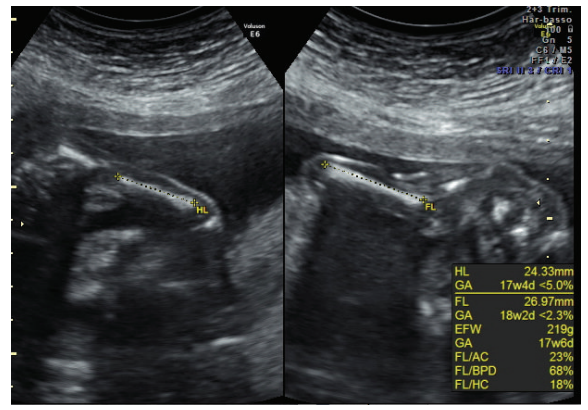

(b)

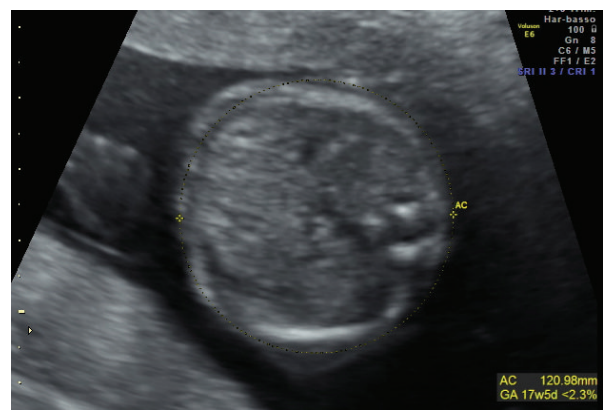

(c)

FIGURE 3: Fetal biometry: biparietal diameter, frontooccipital diameter, and head circumference (a), humerus and femur length (b), and abdominal circumference (c). The parameters resulted under the $5^{\circ} \mathrm{pc}$ of the standard for the gestational age (20 weeks of pregnancy)

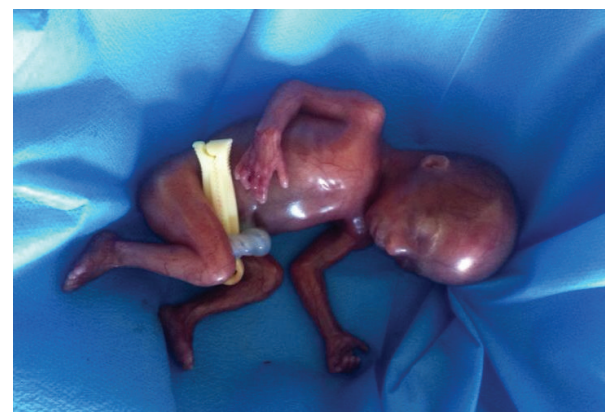

FIGURE 4: Fetal autopsy: it confirmed the absence of major malformations.
According to the reported postnatal pentasomy X cases, in which mental and development retardation were described as the constant relevant signs, genetic counselling was conducted.

Our case shows how prenatal counselling could be difficult: the absence of indicative echographic patterns for chromosomal abnormalities limits the definition of prognosis at birth.

Our patient required genetic counselling only on the base of her advanced maternal age. The influence of the mother's age on the occurrence of penta-X syndrome has not been determined so it could not be considered as risk factor (Table 3 and Figure 5). 
TABLE 2: Postnatal cases and clinical features: review of the literature.

\begin{tabular}{lccc}
\hline Clinical signs & $\%$ & Number of cases & Reference \\
\hline Facial anomalies & 46 & 12 & {$[10,12,14,17-19,21-23,25,28,29]$} \\
Mental retardation & 100 & $24^{*}$ & {$[10-32]$} \\
Developmental retardation & 100 & 26 & {$[10-32]$} \\
Skeletal abnormalities & 61 & 16 & {$[10-13,15-19,22,23,29-31]$} \\
Craniofacial anomalies & 46 & 12 & {$[11,13,15,16,18,28,30-32]$} \\
Cardiovascular anomalies & 58 & {$[10-12,14,15,18,21,23,25,28,30,31]$} \\
\hline
\end{tabular}

${ }^{*}$ Two cases were newborns and mental retardation was impossible to evaluate.

TABLE 3: Maternal age at conception when reported [10-32].

\begin{tabular}{lc}
\hline Maternal age & $\%(21$ cases $)$ \\
\hline$<35$ years & 81 \\
$>35$ years & 19 \\
\hline
\end{tabular}

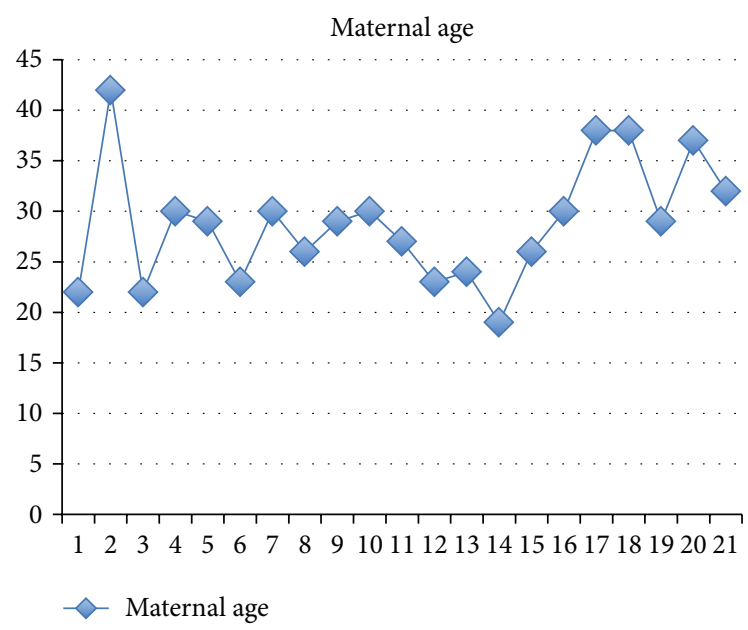

Figure 5: Distribution of maternal age in the 21 cases reported in literature [10-32].

It remains difficult to plan obstetric and gynecological counselling to identify which cases require genetic counselling and fetal karyotype.

At the ultrasound scan we observed an early, symmetric restriction of fetal growth and an increased nuchal fold: such features represent a weak reason for requesting a fetal karyotype. As the literature's review demonstrated most of the major malformations have a late onset so prenatal diagnosis is complicated.

In conclusion, our case emphasised the difficulty of medical practice due to the rarity of the condition, the absence of correlation with advanced maternal age, and the lack of representative ultrasonographic findings.

An early restriction of the fetal growth and an increased nuchal fold associated with an advanced maternal age could suggest referral to a fetal karyotype for further investigation. Fetal autopsy and X-ray represent an essential step for a correct grading of chromosomal abnormalities.
Considering that there is no correlation between advanced maternal age and increased risk for pentasomy $\mathrm{X}$ and the absence of typical echographic signs of this syndrome, the need to include a noninvasive prenatal test (NIPT), which expands clinical coverage to include the $\mathrm{X}$ and $\mathrm{Y}$ chromosomes in routinary prenatal diagnosis as molecular noninvasive tool, and three-dimensional ultrasound to detect any helpful indicative echographic prognostic signs should be evaluated [33].

\section{Take Home Message}

We conclude the following:

(i) no maternal age correlation (from literature);

(ii) mental and development retardation always present;

(iii) clinical phenotype due to $\mathrm{X}$ chromosome dosage defect;

(iv) controversial clinical phenotype among $\mathrm{X}$ chromosome aneuploidies 47, XXX versus 49, XXXXX;

(v) NIPT as routine noninvasive tool screening for young pregnant female.

\section{Conflict of Interests}

The authors declare that there is no conflict of interests regarding the publication of this paper.

\section{References}

[1] L. M. Moraes, L. C. A. Cardoso, V. L. S. Moura et al., "Detailed analysis of X chromosome inactivation in a 49, XXXXX pentasomy," Molecular Cytogenetics, vol. 2, no. 1, article 20, 2009.

[2] A. Kleczkowska, J.-P. Fryns, and H. van den Berghe, "X-chromosome polysomy in the male. The Leuven experience 19661987," Human Genetics, vol. 80, no. 1, pp. 16-22, 1988.

[3] G. E. Sarto, P. G. Otto, E. M. Kuhn, and E. Therman, "What causes the abnormal phenotype in a 49,XXXXY male?" Human Genetics, vol. 76, no. 1, pp. 1-4, 1987.

[4] E. Therman, C. Denniston, G. E. Sarto, and M. Ulber, "X chromosome constitution and the human female phenotype," Human Genetics, vol. 54, no. 2, pp. 133-143, 1980.

[5] C. A. Leal, M. L. Ayala-Madrigal, L. E. Figuera, and C. Medina, "Histone $\mathrm{H} 4$ acetylation analyses in patients with polysomy $\mathrm{X}$ : implications for the mechanism of X inactivation," Human Genetics, vol. 103, no. 1, pp. 29-33, 1998. 
[6] G. Martini, G. Carillo, F. Catizone, A. Notarangelo, R. Mingarelli, and B. Dallapiccola, "On the parental origin of the X's in a prenatally diagnosed 49, XXXXX syndrome," Prenatal Diagnosis, vol. 13, no. 8, pp. 763-766, 1993.

[7] T. D. Myles, L. Burd, G. Font, M. M. McCorquodale, and D. J. McCorquodale, "Dandy-Walker malformation in a fetus with pentasomy X $(49, \mathrm{XXXXX)}$ prenatally diagnosed by fluorescence in situ hybridization technique," Fetal Diagnosis and Therapy, vol. 10, no. 5, pp. 333-336, 1995.

[8] P.-J. Cheng, H.-Y. Chueh, S.-W. Shaw, J.-J. Hsu, T.-T. Hsieh, and Y.-K. Soong, "X pentasomy in an intracytoplasmic sperm injection pregnancy detected by nuchal translucency testing," Fetal Diagnosis and Therapy, vol. 24, no. 3, pp. 299-303, 2008.

[9] P. C. Aytac, E. Tarim, and F. I. Sahin, "Transient hydrops fetalis in a prenatally diagnosed pentasomy X?" Journal of Obstetrics and Gynaecology Research, vol. 38, no. 11, pp. 1335-1338, 2012.

[10] N. Kesaree, P. V. Woolley Jr., and M. Samson, "A phenotypic female with 49 chromosomes, presumably XXXXX. A case report," The Journal of Pediatrics, vol. 63, no. 6, pp. 1099-1103, 1963.

[11] J. Brody, M. G. Fitzgerald, and A. S. D. Spiers, "A female child with five X chromosomes," The Journal of Pediatrics, vol. 70, no. 1, pp. 105-109, 1967.

[12] K. Zajaczkowska, L. Korniszewski, and A. Wolff-Plodowska, "A case of quintuple-X syndrome (49, XXXXX)," Journal of Mental Deficiency Research, vol. 14, no. 4, pp. 305-311, 1970.

[13] F. Sergovich, C. Uilenberg, and J. Pozsonyi, "The 49,XXXXX chromosome constitution: similarities to the 49,XXXXY condition," The Journal of Pediatrics, vol. 78, no. 2, pp. 285-290, 1971.

[14] Y. Yamada and S. Neriishi, "Penta X (49,XXXXX) chromosome constitution: a case report," The Japanese Journal of Human Genetics, vol. 16, no. 1, pp. 15-21, 1971.

[15] L. Larget-Piet, J. Rivron, P. Baillie et al., "Syndrome 49, XXXXX chez une fille de 5 ans," Annales de Génétique, vol. 15, no. 2, pp. 115-119, 1972.

[16] R. Berger, S. Loewe-Lyon, J. Derre, and M. A. Ortiz, "Syndrome 49,XXXXX," Annales de Pediatrie, vol. 20, pp. 965-967, 1973.

[17] M. L. Giovannucci-Uzielli, F. Torricelli, Q. Salvatori, I. Consumi, G. P. Donzelli, and S. Seminara, "Corredo cromosomico 49, XXXXX in una bambina con ipoevolutismo psicofisico," Minerva Pediatrica, vol. 27, pp. 2220-2229, 1975.

[18] R. L. Kaufman, G. S. Sekhon, J. E. Brazy, M. C. Sivakoff, and G. Hatahet, "49,XXXXX syndrome in a neonate”, in New Chromosomal and Malformation Syndromes, D. Bergsma, Ed., OAS XI(5), p. 333, Birth Defects, 1975.

[19] A. Tumba, J. P. Fryns, G. van Ooteghem, and H. van den Berghe, "Le syndrome 49, XXXXX: à propos d'un nouveau cas," L'Unión Médicale du Canada, vol. 106, no. 2, pp. 226-230, 1977.

[20] N. Archidiacono, M. Rocchi, M. Valente, and G. Filippi, "X pentasomy: a case and review," Human Genetics, vol. 52, no. 1, pp. 69-77, 1979.

[21] D. G. Carpenter, J. M. Connolly, C. H. Carter, and K. S. Kanarek, "The penta X (49,XXXXX) syndrome: danger of confusing phenotype with mongolism," The American Journal of Diseases of Children, vol. 133, no. 3, p. 330, 1979.

[22] R. F. Dryer, S. R. Patil, H. U. Zellweger et al., "Pentasomy X with multiple dislocations," The American Journal of Medical Genetics, vol. 4, no. 4, pp. 313-321, 1979.

[23] A. Monheit, U. Francke, B. Saunders, and K. L. Jones, "The penta-X syndrome," Journal of Medical Genetics, vol. 17, no. 5, pp. 392-396, 1980.
[24] S. J. Funderburk, M. Valente, and I. Klisak, "Pentasomy X: report of patient and studies of X-inactivation," The American Journal of Medical Genetics, vol. 8, no. 1, pp. 27-33, 1981.

[25] R. Fragoso, A. Hernandez, M. L. Plascencia, Z. Nazara, R. Martinez y Martinez, and J. M. Cantu, "49, XXXXX syndrome," Annales de Genetique, vol. 25, no. 3, pp. 145-148, 1982.

[26] R. H. Zhang, N. H. Pan, X. F. Li, X. Q. Wang, and M. Wu, "A case of 49,XXXXX syndrome," Chinese Medical Journal, vol. 95, no. 12, pp. 891-894, 1982.

[27] H.-X. Deng, K. Abe, I. Kondo et al., "Parental origin and mechanism of formation of polysomy X: an XXXXX case and four XXXXY cases determined with RFLPs," Human Genetics, vol. 86, no. 6, pp. 541-544, 1991.

[28] R. Kassai, I. Hamada, H. Furuta et al., "Penta X syndrome: a case report with review of the literature," The American Journal of Medical Genetics, vol. 40, no. 1, pp. 51-56, 1991.

[29] M. G. Linden, B. G. Bender, and A. Robinson, "Sex chromosome tetrasomy and pentasomy," Pediatrics, vol. 96, no. 4, pp. 672682, 1995.

[30] A. Boeck, R. Gfatter, F. Braun, and B. Fritz, "Pentasomy X and hyper IgE syndrome: co-existence of two distinct genetic disorders," European Journal of Pediatrics, vol. 158, no. 9, pp. 723726, 1999.

[31] E. Biroli, C. Ghimenti, I. Ricci et al., "Sex chromosome abnormality: report of three clinical cases of X pentasomy," Pathologica, vol. 95, no. 6, pp. 444-446, 2003.

[32] Y. G. Cho, D. S. Kim, H. S. Lee, S. C. Cho, and S. I. Choi, "A case of 49,XXXXX in which the extra X chromosomes were maternal in origin," Journal of Clinical Pathology, vol. 57, no. 9, pp. 10041006, 2004.

[33] C. Samango-Sprouse, M. Banjevic, A. Ryan et al., "SNP-based non-invasive prenatal testing detects sex chromosome aneuploidies with high accuracy," Prenatal Diagnosis, vol. 33, no. 7, pp. 643-649, 2013. 


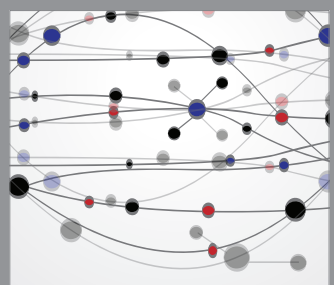

The Scientific World Journal
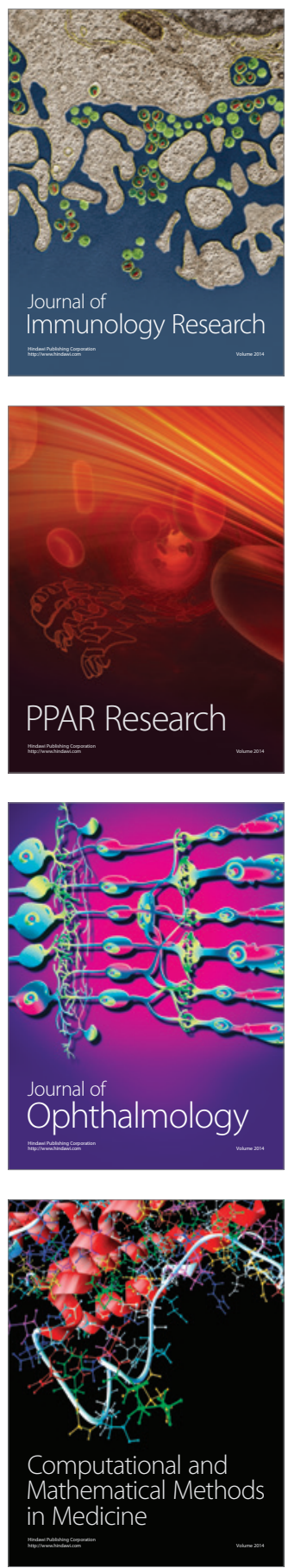

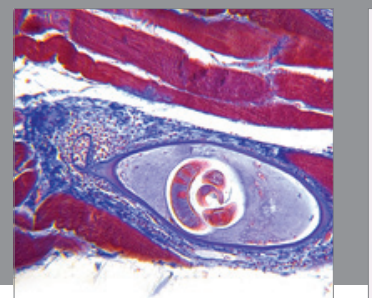

Gastroenterology

Research and Practice
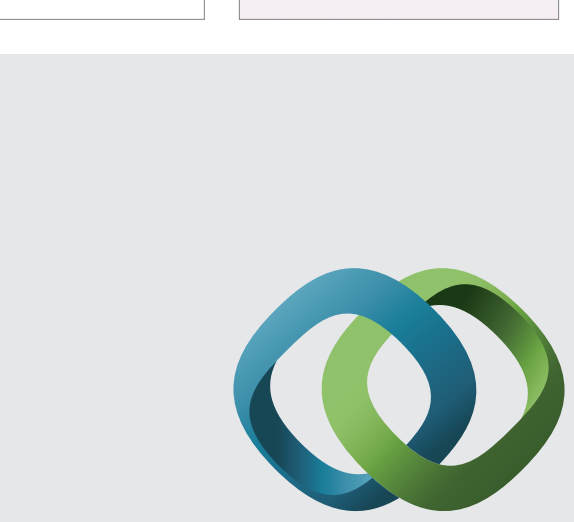

\section{Hindawi}

Submit your manuscripts at

http://www.hindawi.com
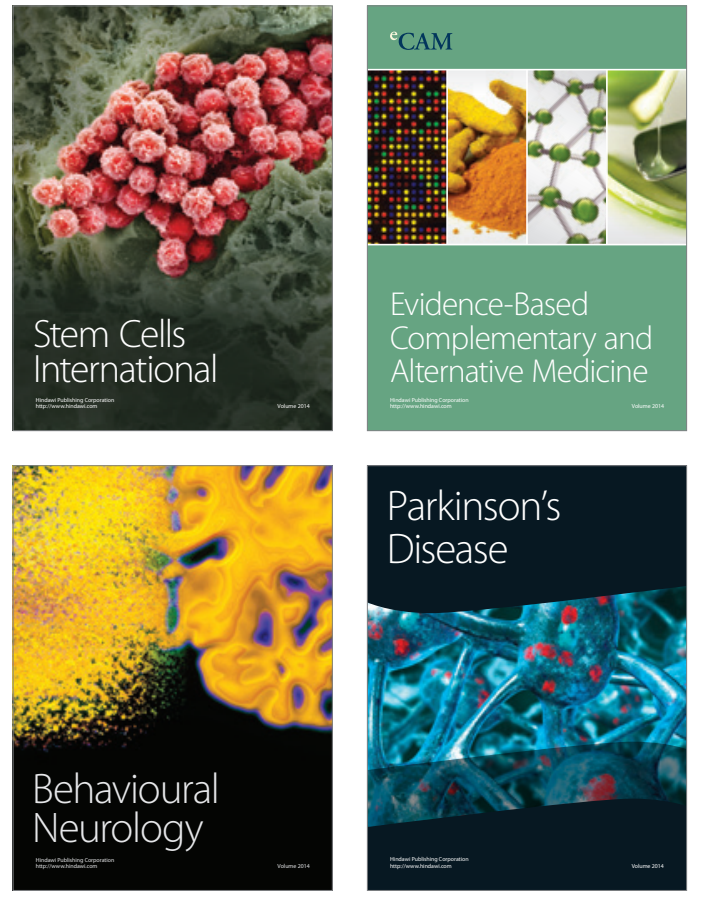
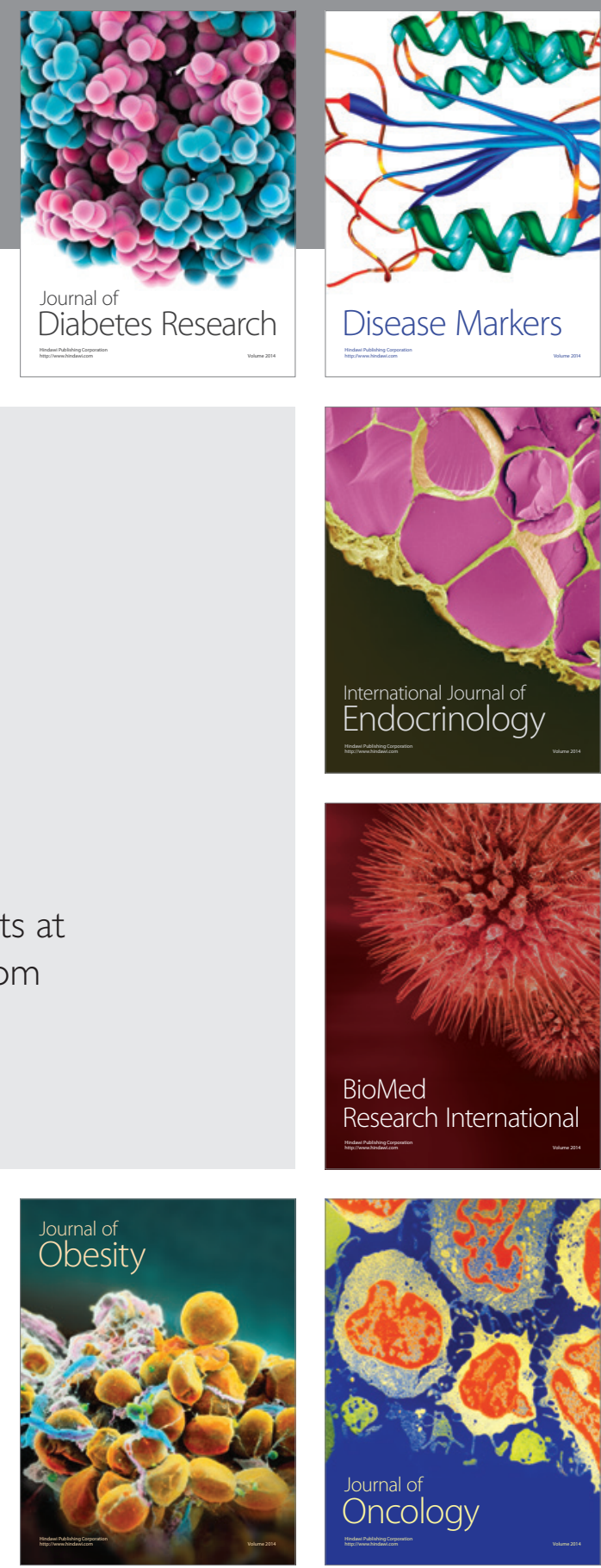

Disease Markers
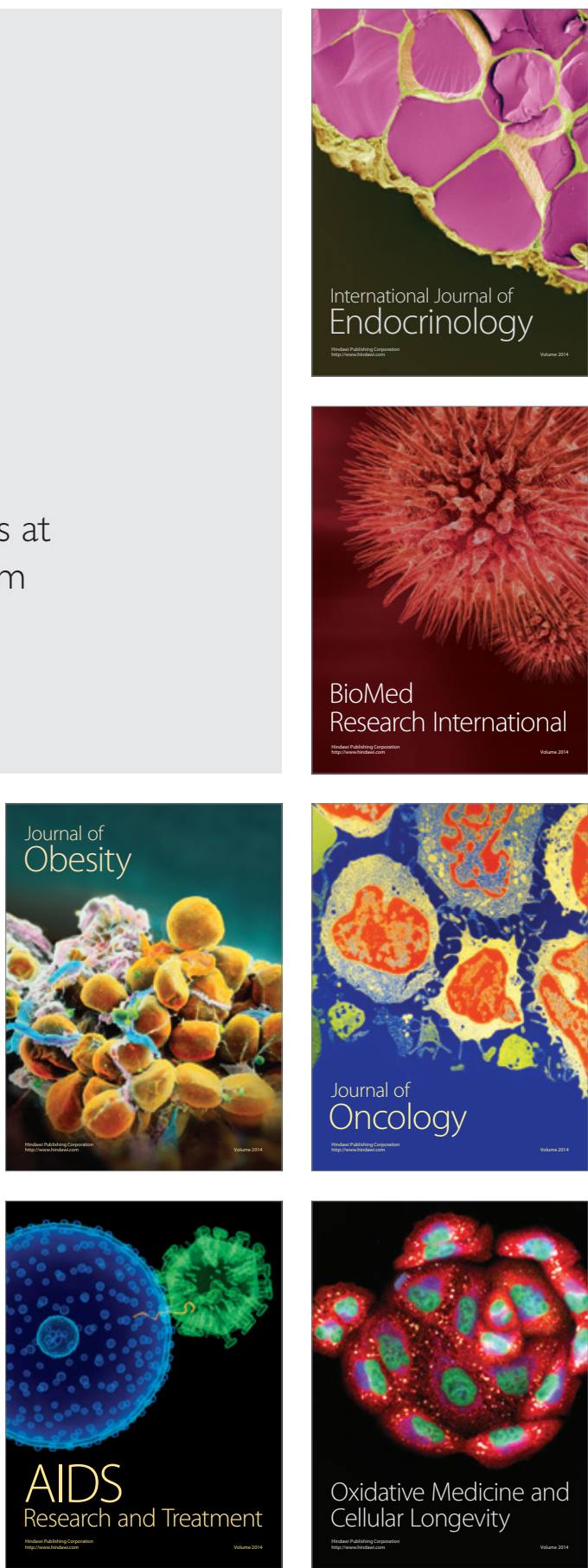